\title{
A Organização Política dos Trabalhadoras/es do SUAS no Âmbito da Proteção Social Básica de Iguatu-CE
}

\author{
Rita de Cássia Clares de Limal ; Antoniel dos Santos Gomes Filho
}

Resumo: A pesquisa reflete o acúmulo de observações quanto a organização política das/os trabalhadoras/es do Sistema Único de Assistência Social e suas principais lutas em defesa da Política Municipal de Assistência Social entre 2015 e 2017. Teve como objetivo analisar o processo de organização política das/os trabalhadoras/es no âmbito do SUAS em Iguatu-CE, com foco na Proteção Social Básica - PSB. A realização da pesquisa deu-se através da aplicação de questionário junto às equipes de nível médio e superior dos Centros de Referências de Assistência Social - CRAS, e uma entrevista semiestruturada com 01 representante do Fórum Municipal de Trabalhadoras/es do SUAS de Iguatu - FMTSUAS.

Palavras chave: Assistência Social. Organização Política. Trabalhadores do SUAS.

\section{The Political Organization of the Workers of SUAS in the Framework of Iguatu-CE's Basic Social Protection}

\begin{abstract}
The research reflects the accumulation of observations regarding the political organization of the workers of the Unified Social Assistance System and its main struggles in defense of the Municipal Social Assistance Policy between 2015 and 2017. The purpose of this study was to analyze the process of political organization of the workers within the scope of the SUAS in Iguatu-CE, focusing on Basic Social Protection (PSB). The survey was carried out through the application of a questionnaire to the middle and upper level teams of the Social Assistance Referral Centers (CRAS), and a semi-structured interview with a representative of the Municipal Workers' Forum (SUAS) of Iguatu - FMTSUAS .
\end{abstract}

Keywords: Social Assistance. Political Organization. SUAS Workers.

\section{Introdução}

O município de Iguatu vivenciou nos últimos anos um intenso processo de lutas e manifestações públicas, a exemplo de outras municipalidades do Brasil. Estas foram

\footnotetext{
${ }^{1}$ Possui graduação em Serviço Social pela Faculdade Vale do Salgado (2012). Especialização em Políticas Sociais e Gestão do SUAS também pela Faculdade Vale do Salgado (2017). Assistente Social do Centro de Referência da Assistência Social do município de Iguatu. Coordenadora Executiva do Fórum Municipal de Trabalhadoras/es do SUAS (FMTSUAS). Compôs a gestão 2014-2017 do Conselho Regional de Serviço Social (CRESS/CE). Possui afinidade com as discussões de Políticas Sociais com ênfase na Política de Assistência Social, Movimentos Sociais e Cidade e Questão Urbana. E-mail: ritaclares.assistentesocial@gmail.com

${ }^{2}$ Mestre em Educação Brasileira pelo Programa de Pós-Graduação em Educação da Universidade Federal do Ceará, com área de concentração em História e Educação Comparada. Docente do curso de Administração da Faculdade Vale do Salgado (FVS). Coordenador do Labora tório Interdisciplinar em Estudos Organizacionais e do Trabalho (LIEOT/ FVS). Professor-pesquisador do Laboratório Interdisciplinar em Estudos da Violência (LIEV/UNILEÃO). Especialista em Gestão de Recursos Humanos pela Faculdade de Juazeiro do Norte (FJN). Tecnólogo em Gestão Comercial pelo Centro Universitário Dr. Leão Sampaio (UNILEÃO). Licenciado em Pedagogia pela Faculdade Kurios (FAK). E-mail:
} antonielsantos@fvs.edu.br/antoniel.historiacomparada@gmail.com

32 Id on Line Rev. Mult. Psic. V.12, N. 40. 2018 - ISSN 1981-1179

Edição eletrônica em http://idonline.emnuvens.com.br/id 
compartilhadas entre pautas de caráter municipal e pautas mais conjunturais, nessa perspectiva a participação das/os servidoras/es públicos municipais por vezes se configurou como força majoritária nas lutas realizadas na cidade.

Estas reivindicações permeavam melhores condições de trabalho, efetivação de direitos trabalhistas negados pelas gestões municipais, manifestações contrárias ao golpe contra a democracia em 2016, resistência às reformas trabalhista e previdenciária, bem como ao intenso processo de desmonte dos direitos sociais, realizado pelo governo golpista de Michel Temer.

A escolha da temática tem por base, além da realidade acima, nossa identificação pessoal e profissional em torno das discussões que versam sobre organização política, participação social e movimentos sociais. Partimos do princípio que muitas dessas intervenções políticas contaram significativamente com a força das/os trabalhadoras/es da política municipal de Assistência Social. Assim, debruçamo-nos a perceber e analisar a organização política destas/es, a partir da percepção das/os profissionais que atuam na Proteção Social Básica - PSB do município.

Adotamos como objetivos, analisar o processo de organização política das/es trabalhadoras/es do SUAS, identificar e analisar as instâncias/experiências políticas e organizativas nas quais as/os trabalhadoras/os da PSB estão inseridas/os, sistematizar o perfil profissional das/os trabalhadoras/os dos CRAS (equipes de nível médio e superior), bem como conhecer a visão das/os trabalhadoras/es sobre a execução da Política Municipal de Assistência Social.

A realização de uma pesquisa deve ter como premissa a possibilidade de contribuir para o processo de construção de novos conhecimentos ou reafirmação de saberes já consolidados, tendo em vista que as análises e descobertas realizadas possibilitam formular e direcionar novos apontamentos a serem pesquisados.

\footnotetext{
Pesquisar é procurar, indagar, questionar o mundo, principalmente aquele que está ao nosso redor. Assim, o primeiro passo do cientista social, enquanto tal consiste em dirigir à realidade um olhar crítico, inquisidor, de modo à - desnaturalizar os fatos sociais. Mas há uma pré-condição para isto: é a ruptura com o senso comum (GONDIM, 1999, p. 27)
}

Metodologicamente, optamos por uma abordagem de cunho qualitativo, por entendermos que esse método de análise possibilitará a percepção de uma maior diversidade de elementos históricos e sociais, os quais podem ser apreendidos através de uma leitura e 
interpretação mais aguçada das informações apresentadas pelos participantes da investigação. Esta abordagem, pode ser melhor explicada como:

\begin{abstract}
Responde a questões muito particulares. Ela se ocupa, nas ciências sociais, com um nível de realidade que não pode ou não deveria ser quantificado. Ou seja, ela trabalha com o universo dos significados, dos motivos, das aspirações, das crenças, dos valores e das atitudes. Esse conjunto de fenômenos humanos é aqui tratada como parte da realidade social, pois o ser humano se distingue não só por agir, mas por pensar sobre o que faz e por interpretar suas ações dentro e a partir da realidade vivida e partilhada com seus semelhantes (MINAYO, 1994, p. 21).
\end{abstract}

Como método de abordagem, adotamos o materialismo histórico e dialético, tendo em vista a possibilidade de melhor interpretar os dados coletados, considerando, pois que as respostas apresentadas devem ser analisadas em uma perspectiva de totalidade, o que possibilitará confrontar e tencionar os dados com a realidade pesquisada.

O método de pesquisa que propicia o conhecimento teórico, partindo da aparência, visa alcançar a essência do objeto. Alcançando a essência do objeto, isto é: capturando a sua estrutura e dinâmica, por meio de procedimentos analíticos e operando a sua síntese, o pesquisador a reproduz no plano do pensamento; mediante a pesquisa, viabilizada pelo método, o pesquisador reproduz, no plano ideal, a essência do objeto que investigou (NETTO, 2009, p. 22).

Portanto a opção por este método torna-se importante, pois proporciona uma maior apreensão da realidade pesquisada, permitindo perceber a historicidade dos sujeitos e a dinâmica da realidade social analisada, considerando-a sua complexidade e seu movimento histórico real, bem como apreender a partir das respostas, os elementos sociais, históricos, econômico, políticos, dentre outros fatores e processos sociais.

Para fins deste estudo realizamos pesquisas bibliográfica e documental, seguida de uma pesquisa de campo. As pesquisas bibliográficas e documentais são, respectivamente, entendidas como uma pesquisa "desenvolvida com base em material já elaborado, constituído principalmente de livros e artigos científicos ao passo que uma pesquisa documental vale-se de materiais que não receberam ainda um tratamento analítico" (GIL, 2002, p. 44-45).

Fundamentamos nossa compreensão em torno da construção histórica da Política de Assistência Social e do SUAS, bem como os acontecimentos e marcos legais que deram base a sua constituição, em Couto (2010), Silva (2013) e Rocha (2016). Utilizamos, ainda, as principais legislações que contornam a política de Assistência Social, dentre elas, a Constituição 
Federal (1988), a Lei Orgânica da Assistência Social - LOAS (1993) e a Política Nacional de Assistência Social - PNAS (2004).

A pesquisa de campo foi realizada no município de Iguatu, o qual pertence à Região Centro Sul do Estado do Ceará e encontra-se localizado a aproximadamente $400 \mathrm{~km}$ da capital do Estado. Este tem uma população de aproximadamente 100 mil habitantes segundo o Instituto Brasileiro de Geografia e Estatística - IBGE (2010) e com base na PNAS (2004) é considerado como município de médio porte (população entre 50.001 a 100.000 habitantes). A escolha pela cidade teve como principal motivador os recentes processos de luta do conjunto de servidoras/es municipais, lideradas/os pelo Sindicato de Servidores Públicos Municipais - SPUMI, e a recente criação do Fórum Municipal de Trabalhadoras/es do SUAS - FMTSUAS.

Nosso campo de pesquisa compreende a Proteção Social Básica do município e o FMTSUAS. A PSB de Iguatu é composta por 06 unidades de CRAS, sendo 05 equipamentos na sede urbana e 01 no Distrito de José de Alencar, distante da sede da cidade, aproximadamente $20 \mathrm{~km}$. O CRAS é uma unidade pública estatal de base territorial, localizado em áreas de vulnerabilidade social, para tanto executa serviços de proteção social básica, organiza e coordena a rede de serviços sócio-assistenciais locais da política de assistência social. O FMTSUAS, criado em 11 de outubro de 2016, constitui-se como espaço político, coletivo, autônomo, apartidário, de organização, construção e deliberação, das/os trabalhadoras/es do SUAS. Para tanto objetiva organizar de forma democrática as/os trabalhadoras/es da Política de Assistência Social de Iguatu-CE.

Definimos como sujeitos da pesquisa, as equipes técnicas de nível médio e superior que compõem a PSB do município. Este universo é composto por 48 profissionais, sendo 24 agentes sociais $^{3}$ e 24 técnicos de nível superior, dentre os quais, assistentes sociais, psicólogas/os e pedagogas/os. Como critério de participação da pesquisa, consideramos a disponibilidade e o desejo das/os profissionais em responder o questionário. No que tange a participação do FMTSUAS optamos por 01 representante, a partir dos critérios de identificação e participação nas atividades de organização política das trabalhadoras/es do SUAS realizadas pelo Fórum.

Como técnicas de coleta, adotamos a aplicação de questionário e a realização de entrevista semiestruturada. A primeira parte se constitui por um questionário que, de acordo com Marconi e Lakatos (2000) é um instrumento de coleta de dados constituído por uma série

\footnotetext{
${ }^{3}$ Agentes Sociais: trabalhadores/as que integram a equipe de referência de nível médio. Em Iguatu são os responsáveis direito pela execução do Serviço de Convivência e Fortalecimento de Vínculo - SCFV. 
de perguntas, que devem ser respondidas por escrito. Ao passo que a entrevista semiestruturada, conforme Minayo (2014) combina perguntas fechadas e abertas, em que o entrevistado tem a possibilidade de discorrer sobre o tema sem se prender a indagação formulada. Deste modo possibilitaremos que as/os pesquisadas/os coloquem o que sentem ou o que pensam sobre a temática.

A pesquisa foi realizada nos meses de julho e agosto de 2017. Para tanto organizamos um questionário, contendo 11 perguntas, as quais foram divididas aleatoriamente entre objetivas e subjetivas e aplicado junto às equipes de nível médio e superior das unidades de Proteção Social Básica (CRAS) da política de Assistência Social de Iguatu. No segundo momento aplicamos a entrevista com 01 representante do colegiado do Fórum Municipal das/os Trabalhadoras/es do SUAS - FMTSUAS.

A sistematização da pesquisa deu-se através da análise do conteúdo colhido na aplicação do questionário e da entrevista. Os dados foram organizados inicialmente um uma planilha, para que pudéssemos sistematizar as respostas dos questionamentos, destacando às ideias centrais e os pontos convergentes e divergentes de cada resposta.

Assim, a análise de conteúdo possibilita "trabalhar com a palavra permitindo de forma prática produzir inferências do conteúdo da comunicação de um texto replicáveis ao seu contexto social e divide-se em, pré-analise, exploração do material e tratamento dos resultados e interpretação (CAREGNATO; MUTTI, 2006, p. 682).

Nossa aproximação com a realidade pesquisada nos fez perceber, dentre outros fatores, o avançado processo de organização política das/os trabalhadoras/es do SUAS na cidade de Iguatu, de sobremodo, sua participação em movimentos e entidades de classes, resultando em efetivas conquistas de direitos e melhores condições de trabalho, ao passo que suscitou a manifestação de novas formas de participação e controle social no bojo da política municipal de Assistência Social. Além disso, evidenciamos claramente que as lutas erguidas por estas/es estiveram pautadas em reivindicações municipais e nacionais, aliadas a atual conjuntura do país. 


\section{Assistência Social Brasileira: Constituição, Efetivação e Contradições do Sistema Único da Assistência Social - SUAS}

A incorporação da Política de Assistência Social como integrante da Seguridade Social brasileira expressa claramente uma histórica conquista da participação popular no processo constituinte, ao passo que materializa anos de lutas em defesa de uma Assistência Social pública e de direito, intencionando, por conseguinte, um processo de ruptura com seu lastro de ações caritativas e benevolentes. Além da Assistência Social, as políticas de Saúde e Previdência formam o tripé da Seguridade Social brasileira.

O marco legal que constitui a Política de Assistência Social no caráter de política pública no Brasil, como atualmente se configura, somente surgiu a partir de uma efervescente participação popular que envolveu vários setores da sociedade brasileira: o período da Assembleia Nacional Constituinte, final do ciclo de governos militares. Este processo resultou na promulgação da Constituição Federal de 1988 (SILVA, 2014, p. 161).

A Constituição Federal de 1988 - CF apresenta a Seguridade Social como "um conjunto integrado de ações de iniciativa dos Poderes Públicos e da sociedade, destinadas a assegurar os direitos relativos à saúde, à previdência e à assistência social” (CF 1988, Art. 194). A CF não apenas eleva a Assistência Social ao status de política pública, como a define como política não contributiva, destinada a quem dela necessitar, além de apresentar seus objetivos.

\footnotetext{
I- a proteção à família, à maternidade, à infância, à adolescência e à velhice;

II- o amparo às crianças e adolescentes carentes;

III- a promoção da integração ao mercado de trabalho;

IV- a habilitação e reabilitação das pessoas portadoras de deficiência e a promoção de sua integração à vida comunitária;

V- a garantia de um salário mínimo de benefício mensal à pessoa portadora de deficiência e ao idoso que comprovem não possuir meios de prover à própria manutenção ou de tê-la provida por sua família, conforme dispuser a lei (CONSTITUIÇÃO FEDERAL, 1988).
}

Ainda nesse contexto de normatização e legalidade, tem-se em 1993 a promulgação da Lei Orgânica da Assistência Social - LOAS. A LOAS, configura-se como um marco na regulamentação da Assistência Social. Seu surgimento tem por base as lutas impressas pelas forças sociais em defesa de uma política de Assistência Social pública, capaz de incidir no enfrentamento das desigualdades sociais, assegurando para tanto, responsabilidade pública estatal. 


\begin{abstract}
A Constituição Federal em vigência no país desde 1988 (Capítulo II, artigos 194 a 204) e a Lei Orgânica de Assistência Social - LOAS (1993) trouxeram a questão para um campo novo: o campo da seguridade social e da Proteção Social pública, campos dos direitos, da universalização dos acessos e responsabilidade estatal, iniciando um processo que tem como horizonte torná-la visível como política púbica e direito dos que dela necessitam. Sem dúvida um avanço, ao permitir que a assistência social, assim posta, transite do assistencialismo clientelista para o campo da Política Social (COUTO, 2010, p. 33).
\end{abstract}

Para além de um direito público e responsabilidade do Estado, a LOAS apresenta em seu Art. $4^{\circ}$, os princípios que regem a Assistência Social. Estes a forjam para consolidação de uma política pública capaz de promover aos seus usuários maiores e melhores condições de acesso e autonomia, em consonância com a participação e controle social e destinação financeira, a fim de garantir continuidade e efetivação dos serviços socioassistenciais.

A LOAS, portanto, representa neste contexto de regulamentação da Assistência Social uma expressiva conquista na sua organização política-administrativa, bem como no estabelecimento de responsabilidades dos entes federados (União, Estado e Municípios), com vista a garantir a execução dos programas, projetos, serviços e benefícios socioassistenciais.

Contudo, cabe destacar que este caminho não foi de todo linear. O processo de contrarreforma do Estado impulsionado pelo modelo econômico neoliberal imprimiu um duro ataque ao conjunto das políticas sociais no Brasil, em especial a Assistência Social. Para Silva (2013) o contexto de expansão do neoliberalismo provocou um intenso processo de contrarreforma do Estado brasileiro, ocasionando à política de assistência social significativas dificuldades de afirmação como política de proteção social, sob a responsabilidade do Estado.

Desde o último terço do século XX, para responder à crise estrutural do sistema do capital, um receituário ofensivo foi, em geral, implementado nas diversas formações econômico-sociais: reestruturação dos processos de acumulação, expresso na chamada acumulação flexível, hegemonia do capital financeiro e políticas de ajuste neoliberal com suas decorrentes contrarreformas no âmbito do Estado (ABRAMIDES; DURIGUETTO, 2014, p. 178).

Acrescido a este processo de desestruturação do Estado brasileiro, tem-se a propagação da chamada "responsabilidade social", que para Iamamoto (2011, p.139) "esta mais para um socialismo conservador burguês". Percebe-se, pois, uma clara estratégia de responsabilização da sociedade no tocante a construção de alternativas de soluções sociais e econômicas, em 
detrimento de investimentos públicos para o fortalecimento e consolidação das políticas sociais brasileiras.

Acirra-se, portanto, a lógica neoliberalista de que cada cidadão pode construir sua própria história de sucesso, desconsiderando as determinações sócio-históricas que fomentaram a construção do Estado Brasileiro. Este modelo visa à criação de "parcerias" com a sociedade civil, na perspectiva de conjugação de esforços, em que todos são responsáveis e chamados a contribuir com o enfrentamento da pobreza. É neste cenário que vai eclodir o surgimento e o crescimento do chamado Terceiro Setor (SILVA, 2013, p. 47).

Gesta-se, portanto, as condições necessárias para consolidação de um projeto político e econômico comprometido sumariamente com a construção de um "Estado mínimo para os trabalhadores e máximo para o capital" (SANTOS, 2007, p. 20).

Deste modo os anos que seguiram foram de contínua regressão e desregulamentação da política de Assistência Social, secundarizando substancialmente os ganhos assegurados com a promulgação da LOAS. As investidas neoliberais sobre o Estado brasileiro foram fundamentais para o descaso e desorganização da Política de Assistência Social nos anos seguintes à sua regulamentação.

Cabe destacar, que estas ofensivas foram respondidas com luta e resistência pela classe trabalhadora, o que possibilitou à política de Assistência Social, sobretudo na última década, uma nova reconfiguração enquanto política pública, desta feita com rico arcabouço legal e normativo que possibilitou definir melhor sua organização política administrativa, estabelecendo responsabilidades financeiras, formas de controle e participação social, recursos humanos e sistema de monitoramento e avaliação. Este processo promoveu a ambiência favorável à construção da Política Nacional de Assistência Social - PNAS e deu bases sólidas para implantação e implementação do Sistema Único de Assistência Social - SUAS.

\section{A Política Nacional de Assistência Social e as Bases para Implantação do SUAS: um Marco na Efetivação da Assistência Social no Brasil}

Desde a Constituição Federal de 1988 que a Assistência Social vivencia contraditórios processos de avanços e retrocessos na perspectiva de torna-se uma política pública e de direito. Entretanto, a última década foi terreno fértil para criação de legislações e regulamentações 
imprescindíveis a uma maior organização política e administrativa da Assistência Social em todo o território brasileiro.

Após uma década da promulgação da LOAS, tem se a criação da Política Nacional de Assistência Social - PNAS, em 2004. Como marco desta conquista tem-se a realização da IV Conferência Nacional de Assistência Social em dezembro de 2003, com o tema: "Assistência Social como Política de Inclusão: Uma Nova Agenda para a Cidadania - LOAS 10 anos”.

Segundo Rocha (2016), para realização de Conferências previa-se intervalos de 04 anos entre um evento e outro, portanto a IV Conferência deveria acontecer somente em 2005, porém, no governo Lula, foi estabelecido um intervalo de 02 anos, coincidindo assim que a IV Conferência de Assistência Social tivesse sua abertura no mesmo dia em que a LOAS completava 10 anos.

De acordo com Silva (2013) a IV Conferência é um marco na luta pela consolidação das diretrizes aprovadas na LOAS, bem como uma baliza imprescindível na regulamentação da área pelas importantes discussões e deliberações realizadas, expressando ainda o acúmulo de lutas que contribuíram decisivamente para a implementação do Sistema Único de Assistência Social - SUAS. Nesta perspectiva a aprovação da PNAS materializa as deliberações da IV Conferência, definindo as bases de um novo padrão de gestão para a assistência social, ao passo que a Norma Operacional Básica do Sistema Único de Assistência Social - NOB/SUAS (2005) regulamenta a implementação do SUAS.

Esta dupla conquista torna-se instrumentos centrais para oferta de uma política cada vez mais pública e estatal, ao passo que reafirma seu caráter não contributivo, assegurando, sobretudo, a cobertura dos benefícios, serviços, programas e projetos a quem dela necessitar.

\footnotetext{
A Política de Assistência Social, de caráter não contributivo e direcionada para quem dela necessitar, tem na Política Nacional de Assistência Social (PNAS), aprovada pelo Conselho Nacional de Assistência Social (CNAS) em 2004, e no Sistema Único de Assistência Social (SUAS), em implantação no Brasil desde 2005, os dois instrumentos políticos e normativos mais recentes. Ambos objetivam o avanço da Assistência Social enquanto Política Pública (COUTO, 2010, p.16).
}

A implantação do SUAS torna-se, portanto, uma das principais deliberações da IV Conferência, ao passo que prevê que sua implementação acontecerá de forma descentralizada, regionalizada e hierarquizada, de base territorial e com clara definição das competências, atribuições, fontes e formas de financiamento (ROCHA, 2016). Este processo é precedido pelo 
estabelecimento da PNAS, a qual prevê a direção, os conteúdos e os objetivos do SUAS. Quanto aos seus princípios, a PNAS conserva basicamente os mesmos princípios da LOAS, acrescidos apenas da centralidade familiar para concepção e implementação dos benefícios, serviços, programas e projetos (ROCHA, 2016, p. 116).

No que concerne à organização da Assistência Social, a PNAS estabelece dois tipos: Proteção Social Básica e Proteção Social Especial, de média e alta complexidade, considerando para tanto os níveis de vulnerabilidade e risco social dos indivíduos, famílias e/ou grupos sociais. As ações previstas em cada Proteção se configuram sob a perspectiva socioterritorial, prevê a garantia dos direitos sociais a quem dela necessitar e organiza político administrativamente a execução da Assistência Social em todo o Brasil. Visa, ainda, a articulação com outras políticas sociais e territoriais, com vista a garantir os direitos e a dignidade dos seus usuários.

Ainda de acordo com a Política, a proteção social deve garantir as seguintes seguranças: de sobrevivência, por meio de benefícios continuados e eventuais; segurança de convívio, através de ações, cuidados e serviços que restabeleçam vínculos pessoais, familiares, mediante a oferta de vivências e experiências socioeducativas, lúdicas e socioculturais, e segurança de acolhida, através de ações, cuidados, serviços e projetos, os quais promovam a autonomia, a capacidade de convívio e protagonismo dos usuários.

As ações, serviços, programas e projetos desenvolvidos pela Assistência Social, conforme a PNAS, organizam-se em rede, destinam-se às populações que vivem em situação de vulnerabilidade social decorrente da pobreza, privação (ausência de renda, acesso precário ou inexistente aos serviços públicos, dentre outros) e/ou, fragilização de vínculos afetivos (relacionais e de pertencimento social) e objetivam prevenir situações de risco e fortalecer vínculos familiares e/ou comunitários, ampliando, portanto, as possibilidades de garantia dos direitos aos seus usuários.

O CRAS é uma unidade pública estatal descentralizada da política de assistência social, responsável pela organização e oferta de serviços da proteção social básica nas áreas de vulnerabilidade e risco social dos municípios. Caracteriza-se como a principal porta de entrada da política de Assistência Social, bem como de acesso às demais políticas sociais. Apresenta por objetivo prevenir a ocorrência de situações de vulnerabilidades e riscos sociais nos territórios e para isso desenvolve todos os serviços socioassistenciais no seu território de 
abrangência. Estes serviços tem caráter preventivo, protetivo e proativo (ORIENTAÇÕES TÉCNICAS DO CRAS, 2009).

Objetivando a organização dos serviços oferecidos na Proteção Social Básica, o Conselho Nacional de Assistência Social - CNAS, através da resolução n ${ }^{\circ} 109$ de novembro de 2009, prevê o funcionamento do CRAS a partir três serviços: Serviço de Proteção e Atendimento Integral à Família - PAIF; Serviço de Convivência e Fortalecimento de Vínculos - SCFV e Serviço de Proteção Social Básica no domicílio para pessoas com deficiência e idosas.

De acordo com a Tipificação, estes serviços, combinados, visam o fortalecimento da função protetiva das famílias, fortalecimento dos vínculos familiares e comunitários, prevenção de ocorrências de risco social, desenvolvimento de ações intergeracionais e a heterogeneidade, garantia de desenvolvimento de mecanismos para inclusão social e autonomia das pessoas com deficiências e pessoas idosas, prevenindo situações de risco, exclusão e isolamento.

A implantação do SUAS consolida portanto um intenso processo de lutas em defesa de um maior organização política e administrativa da Assistência Social desde sua previsão constitucional em 1988. Esta importante conquista foi travada, substancialmente, pelo chamado "campo assistencial" e revela um processo de mudanças entre o novo e o velho na política de Assistência Social no Brasil (COUTO, 2010).

Está lançado, pois, o desafio de seguir na defesa das condições necessárias à implementação do SUAS em consonância com suas previsões legais, as quais são imprescindíveis para assegurar a descentralização político-administrativa, a gestão do trabalho, o financiamento, a participação e controle social, o planejamento, monitoramento e avaliação e a defesa da política de recursos humanos consonante com as perspectivas lançadas sobre a implementação de um SUAS público, forte e capaz de reafirmar o papel político estatal da Assistência Social.

Este processo, além de representar a maturação política e legalística da Assistência Social, incorpora as demandas presentes na sociedade brasileira e reitera as diretrizes para efetivação de uma Política substancialmente pública e de direito, sob responsabilidade do Estado, com vista ao enfrentamento e superação de práticas assistencialistas e/ou caritativas que historicamente vincularam-se a Assistência Social.

Entretanto, no atual cenário do país, estes avanços encontram-se fortemente ameaçados, em virtude do aligeirado processo desmonte do Sistema de Proteção Social Brasileiro. O governo federal vem impondo uma séria de medidas e contrarreformas que visam 
substancialmente precarizar e acabar com os direitos sociais e as garantias constitucionais previstas pela Constituição Federal de 1988.

Em uma análise mais geral sobre estas medidas, três delas expressam claramente o cenário perverso que contorna as/os trabalhadoras/es brasileiras/os: a Emenda Constitucional 95, congela os gastos sociais por 20 anos, a Reforma Trabalhista, altera substancialmente a Consolidação das Leis Trabalhistas - CLT ${ }^{4}$ e a Proposta de Emenda a Constituição 287/2016 que propõe novas regras de acesso a Previdência Social, bem como ao Benefício de Prestação Continuada - BPC.

A Assistência Social e o SUAS não estão ilesos a este desmonte. Programa como "Criança Feliz", capitaneia o avançado processo de desconstrução do SUAS, bem como a retomada de uma Assistência Social focalizada, seletiva, e, sobretudo, assistencialista. Aliada a esta iniciativa temos ainda, alteração nos critérios de acesso ao Benefício de Prestação Continuada - BPC, recorrentes cortes no número de famílias atendidas pelo Programa Bolsa Família e a drástica redução no orçamento do SUAS, o que compromete a execução dos serviços, programas e projetos estruturados nos último anos ${ }^{6}$.

Importante frisar que em contraponto a estes ataques e cientes do quão perigoso os são para a população que necessita da Assistência Social, há em todo país um sentimento de luta e resistência em defesa do SUAS e de suas garantias democráticas. Não se concebe que décadas de lutas sejam agora transformadas em ações pontuais, clientelistas, voluntaristas e conservadoras, práticas que a Assistência Social vinha se distanciando gradativamente desde sua incorporação à seguridade social brasileira.

Reafirmamos, portanto, a urgente necessidade da defesa intransigente do SUAS, enquanto Sistema público, fruto de uma longa e coletiva construção, o qual prevê, organiza e assegura os serviços socioassistenciais à milhões de brasileiros sob a primazia do Estado, em consonância com a efetivação de uma Política de Assistência Social pública, universal e de direito.

\footnotetext{
${ }^{4}$ Maiores informações, conferir: 〈http://www25.senado.leg.br/web/atividade/materias/-/materia/129049>.

${ }^{5}$ Maiores informações, conferir: <http://www.planalto.gov.br/ccivil_03/_Ato2015-2018/2016/Decreto/D8869.htm>.

${ }^{6}$ Para melhor compreender este cenário, conferir: <https://maissuas.org/2017/09/07/na-festa-da-independencia-o-anuncio-do-fim-dosuas/?blogsub=confirming\#blog_subscription-3>. e <https://maissuas.org/2017/09/08/orcamento-suas-2018-do-governo-federal-inviabilizaassistencia-social-no-pais/ > 


\section{A Organização Política e as Lutas das/os Trabalhadoras/es do SUAS em Iguatu-CE: Interlocução entre a Conquista de Direitos e a Defesa da Política Municipal de Assistência Social}

O processo de estruturação do SUAS exigiu historicamente que as/os trabalhadoras/es da política de Assistência Social desenvolvessem estratégias de enfrentamento das práticas assistencialistas que sempre contornaram a execução da mesma. A promulgação da NOB/RH/SUAS em 2005, consoantes com o princípio de participação democrática e controle social previstos no SUAS, possibilitou uma maior identificação e clareza do papel das equipes de referência dos equipamentos sociais vinculados a política de Assistência Social

Neste processo, emergem, sobretudo, as organizações de trabalhadoras/es e usuárias/os, sobretudo em fóruns, os quais se constituíram como ferramenta de organização política destas/es, bem como de defesa dos direitos socioassistenciais, consoantes com as garantias constitucionais e reforçadas pelo SUAS desde sua promulgação em 2011.

Neste contexto, traremos a seguir um debate sobre os dados colhidos na nossa pesquisa, a qual anseia analisar o processo de organização política das/os trabalhadoras/os no âmbito do SUAS em Iguatu, considerando para tanto o perfil destas/es profissionais, os espaços sócioocupacionais em que estão inseridas/os, sua inserção em espaços de organização política, as principais lutas travadas nos últimos anos, bem como sua avaliação sobre a política municipal de Assistência Social.

Nossa análise intenta considerar, sobremaneira, a totalidade social em que as/os trabalhadoras/es estão inseridas/os, bem como não negar ou desconsiderar os elementos que se colocam como contradições e limitações para o processo de organização política dessas/es profissionais.

\section{O perfil profissional das/os trabalhadoras/os}

Após a análise dos dados, constatamos que do total de 48 profissionais, 33 responderam a pesquisa, ou seja, $68,75 \%$ do universo pesquisado, sendo 24 do sexo feminino e 09 do sexo masculino. Destas/es, 19 são da equipe de nível médio (agentes sociais) e 14 são da equipe de nível superior, dentre as/os participantes da equipe de nível superior, temos 06 assistentes sociais, 04 psicólogas/os e 04 pedagogas/os. 
A presença majoritária de profissionais do sexo feminino nos remete ao processo de feminização da política de assistência social que historicamente teve suas atividades centralizadas na perspectiva de cuidado e caridade, práticas compreendidas como de responsabilidade da mulher.

\begin{abstract}
A história da política da Assistência Social pousa suas raízes nas ações de caridade e benemerência realizadas especialmente, pelas Damas de caridade, mulheres de elevado poder aquisitivo, destacadamente, as primeiras-damas. Desde o seu germe, portanto, há uma nítida marca de gênero como construto da Assistência Social (CISNE, 2007, p.01).
\end{abstract}

Importante destacar que esta associação remonta à criação da Legião Brasileira de Assistência - $\mathrm{LBA}^{7}$, no governo do presidente Getúlio Vargas, o qual designou como presidenta a primeira dama Darcy Vargas. Desde então se gestou a equívoca compreensão de que caberia à primeira-dama a gestão da política de assistência social, numa perspectiva de ações pautadas para o "cuidado" com os pobres.

Ainda sobre o perfil das/os informantes identificamos que a faixa etária destas/es está compreendida entre 20 e 40 anos, sendo que 24 tem entre 20 a 30 anos, 06 entre 31 a 40 anos e 03 acima de 40 anos. No que tange ao processo de formação, 04 possuem ensino médio, 08 graduação completa, 09 graduação incompleta, 09 pós-graduação completa e 03 pós-graduação incompleta.

Destacamos que para investidura no cargo de agente social a exigência de escolaridade é apenas ensino médio completo, contudo, na referida categoria 15 profissionais já estão inseridos no ensino superior, sendo 06 com graduação completa e 09 em processo de graduação. Quanto à equipe de nível superior constatamos que 12 estão em nível de pós-graduação, sendo que 03 ainda não concluíram.

Os dados elucidam importantes e significativos avanços na gestão do trabalho no âmbito do SUAS. O processo de profissionalização da Assistência Social, o qual é fruto de muitas lutas em defesa da oferta e da qualidade dos serviços socioassistenciais, não é apenas uma conquista alcançada neste período, mas igualmente expressa que a efetivação dos objetivos do SUAS

\footnotetext{
7 A primeira grande instituição pioneira da assistência social no Brasil, a Legião Brasileira de Assistência, é organizada em sequência ao engajamento do país a Segunda Guerra Mundial. objetivo declarado de seu surgimento era "o de "prover as necessidades das famílias cujos chefes haviam sido mobilizados, e, ainda, prestar decidido concurso ao governo em tudo que se relaciona ao esforço da guerra" (IAMAMOTO; CARVALHO, 1982, p. 251) 
perpassa substancialmente pela definição das competências/habilidades técnicas e clareza das/os profissionais demandadas/os em cada serviço.

Nesta perspectiva destacamos que a instituição da Norma Operacional Básica de Recursos Humanos-NOB-RH/SUAS, através da resolução No 269/2006 do Conselho Nacional de Assistência Social, tornou-se uma destas grandes conquistas do SUAS ao reafirmar que,

[...] a assistência social deve ofertar seus serviços com o conhecimento e compromisso ético e político de profissionais que operam técnicas e procedimentos impulsionadores das potencialidades e da emancipação de seus usuários" (NOB-RH/SUAS, 2011, p. $19)$.

No que tange a carga horária, a grande maioria, ou seja, 27 profissionais trabalham 40 horas semanais. Apenas 06 , todas/os assistentes sociais, trabalham 30 horas semanais. ${ }^{8}$ Quanto ao vínculo profissional das/os trabalhadoras/es, que 31 são estatutários e 02 estão sob regime de contrato temporário. Sobre o tempo de atuação em CRAS, alcançamos que 01 trabalha a menos de 01 ano, 19 trabalham entre 01 a 03 anos, 11 estão entre 03 a 05 anos e 02 estão a mais de 05 anos.

Esta constatação revela os avanços obtidos na cidade de Iguatu, nos últimos anos, no que tange a realização de concursos públicos municipais. Esta conquista possibilitou encerrar um longo ciclo de apadrinhamento político e acordos eleitorais na escolha das/os trabalhadoras/es da Assistência Social, expressão clara de condições de trabalho precarizadas, contratações sob modalidade de licitação, bem como serviços descontinuados e por vezes em desacordo com os objetivos da PNAS.

A NOB-RH estabelece claramente que a gestão do trabalho no âmbito do SUAS visa ainda, dentre outros objetivos, "garantir a "desprecarização" dos vínculos dos trabalhadores do SUAS e o fim da terceirização". Esta demarcação torna-se de fundamental importância para a continuidade e qualidade dos serviços, bem como para autonomia das/os profissionais, uma vez não subjulgadas/os ao querer da gestão, podem reivindicar melhores condições de trabalho, bem como lutar pela qualidade dos serviços ofertados na política de assistência social.

Esta análise pode melhor ser compreendida na fala do informante 13. "A realização dos últimos concursos fortaleceu a participação dos trabalhadores, com este fortalecimento temos

\footnotetext{
${ }^{8}$ A Lei Federal 12.317, de 16 de agosto de 2010 assegurou a duração do trabalho da/o Assistente Social em 30 (trinta) horas semanais". 
trabalhadores mais seguros e participativos". A NOB-RH/SUAS prevê que o acesso á carreira estar condicionada à aprovação em concurso público de provas ou provas e títulos.

Essa diretriz alinha as condições de contratação dos trabalhadores da política de assistência social ao artigo 37 da Constituição Federal ao instituir o concurso público como meio de acesso aos cargos de equipes de referências dos CRAS e CREAS. A contratação por meio de concurso público institucionaliza o servidor público como seu representante legal, tendo este a responsabilidade e a função de representar o Estado (NOB-RH/SUAS, 2011, p. 47).

\section{Instâncias e experiências políticas e organizativas das/os trabalhadoras/os e a luta por melhores condições de trabalho}

No intento de identificar os principais espaços de participação e organização política das/os trabalhadoras/es, questionamos sobre suas formas de organização coletiva, participação e avaliação das lutas travadas na cidade de Iguatu.

No que tange a organização política, obtivemos como resposta que 21 são sindicalizadas/os, 02 integram o FMTSUAS, 05 não responderam, 04 participam de partidos políticos, grupos culturais e movimentos de igrejas e apenas 01 disse não participar de nenhuma organização política.

Os dados revelam que a grande maioria das/os pesquisadas/os participam de alguma organização coletiva. Esta manifestação nos revela que majoritariamente as/os trabalhadoras/es estão politicamente organizadas/os, o que possibilita maiores condições de lutas sociais, bem como defesa da execução de uma política municipal de assistência social consoante com as diretrizes do SUAS, uma vez que percebemos que as pautas de caráter trabalhista estavam aliadas as pautas de melhorias dos serviços ofertados as/os usuárias/os.

A “participação social é considerada um dos aspectos inovadores do SUAS” (COUTO, 2010, p.119). Neste sentido, as respostas obtidas podem ser compreendidas como materialização desta inovação, embora entendemos que este processo tenha se dado de forma espontânea, ao passo que pode ser ainda também consideradas como novas alternativas de participação e controle social no âmbito da Assistência Social, possibilitando sua extensão para além dos espaços tradicionais de controle social, a exemplo dos conselhos de direitos e conferências de políticas públicas. 
A PNAS nos coloca que "na conformação do SUAS, os espaços privilegiados onde se efetivará essa participação são os conselhos e as conferências, não sendo, no entanto, os únicos, já que outras instância somam força a esse processo". Em outra perspectiva importa colocar que esta perspectiva promove uma maior abertura democrática no bojo da Assistência Social garantindo legitimidades as diversas formas de organização e participação social/política, para além de representar, uma alteração no padrão de relacionamento do Estado com a sociedade civil (COUTO, 2010, p.119).

Sobre a participação nas lutas realizadas na cidade nos últimos anos, considerando para tanto o intervalo entre 2015 a 2017, colhemos que 25 participaram em algum momento das paralisações, greves e ato de ruas, 03 não participaram e 05 não responderam.

Evidenciamos, portanto, que a grande maioria das/os informantes participou das intervenções políticas realizadas na cidade. Esta constatação revela, sobretudo, uma maior segurança das/os trabalhadoras/es para participar das lutas, haja visto serem servidoras/es estatutárias/os com maior autonomia, não ficando expostas/os a demissões por se organizarem ou se posicionarem em defesa de seus direitos.

Para, além disso, é importante destacar que a realização destas atividades, combinadas com os processos de formações realizadas na cidade neste período (seminários, fóruns, palestras, debates, etc) provocaram uma nova cultura de participação e organização das/os trabalhadoras/es, o fortalecimento das entidades de classe, a exemplo dos Sindicatos, e o surgimento de novas organizações políticas, como o FMTSUAS.

O FMTSUAS surgiu da articulação das/os trabalhadoras/es do município, suscitado pelo Conselho Estadual de Assistência Social - CEAS, Conselho Regional de Serviço Social -

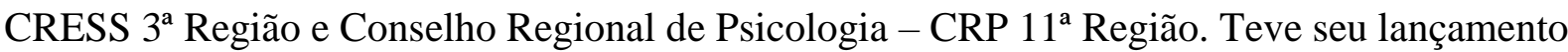
em 11 de outubro de 2016 com um Seminário Municipal, o qual não apenas aprovou a criação do Fórum, mas, sobretudo, discutiu com o conjunto das/os trabalhadoras/es a atual conjuntura do país e os impactos para o SUAS.

Para a Secretária Geral do FMTSUAS e representante do Fórum, a criação deste espaço de organização política representa uma importante conquista das/os trabalhadoras/os do SUAS em Iguatu, a medida que para esta tem promovido um extraordinário crescimento profissional. Destaca ainda que o FMTSUAS vem se tornando uma referência no estado do Ceará e que hoje já percebe as/os trabalhadoras/es trazendo suas demandas, o que antes acontecia apenas com o Sindicato Municipal. 
O FMTSUAS é um espaço que muito me orgulha de estar ajudando a construir, tenho aprendido muito com as/os companheiras/os que fazem parte do fórum, isso tem sido de grande valia pra mim, enquanto profissional [...] o fórum tem sido importante porque ele ta articulando os trabalhadores do SUAS, tem sido uma referência no estado para os trabalhadores, no estado (Ceará) ele ta sendo reconhecido cada vez. mais [...] serve de exemplo pra outros municípios, e, os trabalhadores/as acabam, quando tem alguma demanda chegam também ao fórum não somente ao sindicato, tem sido um elo de articulação para os trabalhadores do SUAS, para os trabalhadores da Assistência Social (ENTREVISTADA FMTSUAS).

A fala da entrevistada revela a importância do surgimento do FMTSUAS para organização e articulação das/os trabalhadoras/es. Esta percepção corrobora com o que afirmamos acerca da implantação do SUAS e a criação de outros espaços de organização e participação social, os quais vem fomentando e democratizando a participação dos sujeitos envolvidos na política de Assistência Social. ${ }^{9}$

No que tange a avaliação das conquistas alcançadas através das lutas realizadas na cidade, obtivemos que estas iniciativas em sua maioria contribuíram para o processo de mobilização e fortalecimento das/os trabalhadoras/es, representaram um importante instrumento de resistência e pressão coletiva, possibilitando conquistas de direitos e melhores condições de trabalho.

Os processos de luta e mobilizações no município desenvolveram e se intensificaram, tiveram muitos resultados positivos, podemos observar algumas conquistas $e$ garantias de direitos. É preciso que haja conscientização, a união tendo como principal objetivo a valorização do servidor público (INFORMANTE 11).

Participei em 2014 e 2015 de paralisações gerais, assembleias sindicais, penso serem instrumentos oportunos de resistência da classe trabalhadora que contribuem efetivamente para afirmação de direitos (INFORMANTE 09).

Estas constatações foram também encontradas na fala da representante do FMTSUAS. Para ela, todo este processo tem gerado conquistadas significativas para as/os trabalhadoras/es do SUAS em Iguatu, a exemplo do adicional de periculosidade, que atualmente algumas categorias recebem, a mesma coloca que este direito precisa sem ampliado, o que implica ter uma postura de resistência para que novas conquistas aconteçam.

\footnotetext{
${ }^{9}$ Atualmente no âmbito do SUAS, além dos conselhos de direitos, conferências municipais, estaduais e federal, existem também os Fóruns de Trabalhadoras/es do SUAS ( a nível nacional, estadual e municipal), os Fóruns de usuários/as do SUAS e os Fóruns de Secretários de Assistência Social. 
A gente ver que há de certa forma conquistas para a classe trabalhadora, não somente a luta, a luta tem se transformado em conquistas, né, lógico que a gente sabe que a luta não pode parar, a gente conquista, luta para conquistar mais direitos (ENTREVISTADA FMTSUAS).

Para outro, são processos que tem criado servidores mais críticos, conhecedores de seus direitos e deveres. Por meio dessas mobilizações foram conquistados direitos que historicamente foram negados (INFORMANTE 07).

No que tange as lutas de forma mais ampla, o informante 06 afirma que foram "momentos de fortalecimento do povo, onde o objetivo foi lutar pelos direitos de todos. E a luta continua, nenhum direito a menos"!

O entrevistado 23 corrobora com a dimensão ampliada das lutas e reitera "participei em vários momentos importantes; greve geral de 2015, assembleias e recentemente contra as reformas, trabalhista e previdenciária, grifo nosso".

As questões apresentadas nas falas, bem como as reflexões extraídas dos dados levantados revelam a importância e a necessidade da organização da classe trabalhadora para defesa e manutenção dos direitos sociais e trabalhistas historicamente conquistados. Para, além disso, evidenciamos que são nestes processos coletivos e plurais que torna-se possível reafirmar a (nossa) identidade de classe trabalhadora, a qual anseia não apenas participar da produção das riquezas, mas igualmente acessá-las através de melhores condições de vida, materializadas, sobretudo, na efetivação de direitos sociais constitucionalmente previstos.

O direito social depende da vivência concreta da democracia política para que as pessoas excluídas do sistema econômico ou incluídas numa lógica de exploração possam se organizar para questionar criticamente a realidade, expondo publicamente os seus problemas e reivindicando as soluções necessárias [...] permitindo que a democracia seja de fato exercida, especialmente no sentido de permitir a organização dos diversos segmentos da sociedade, a fim de que conduzam, mediante ações concretas, suas reivindicações, ao mesmo tempo que expressem com clareza sua vontade e sua indignação contra os fatores agressivos á efetivação dos direitos constitucionais sociais (MARICATO, 2013, p.87).

\section{Avaliação das/os trabalhadoras/es acerca da política municipal de assistência social}

Ao discutirmos sobre a avaliação que as/os profissionais fazem da política municipal de Assistência Social, colhemos que 07 a acham ruim, 05 a veem como boa e 21 avaliam de forma regular. 
Aos debruçarmos sobre os aspectos apresentados por aquelas/es que avaliam como ruim, os principais apontamentos relacionam-se a ausência de planejamento/gestão da política, de forma mais geral e participativa, bem como o diálogo entre os gestores e as/os trabalhadoras/es.

Na minha opinião a Política de Assistência Social ainda precisa evoluir, não só em relação a garantia de direitos dos usuários, mas também em relação a própria gestão. Aqui os gestores não mantém diálogo com os servidores, sendo necessário muitas vezes recorrer ao sindicato [...] (INFORMANTE 02).

Ainda nesta perspectiva, colhemos do informante 01 " [...] Na minha opinião a falta de diálogo entre a gestão e os servidores só aumenta a cada dia, prejudicando significativamente o bom andamento do serviço".

Estas colocações revelam o desafio de se efetivar uma das diretrizes do SUAS, “participação da população, por meio de organizações representativas, na formulação das políticas e no controle das ações em todos os níveis" (BRASIL, 1993), suscitando investimentos em processo de maior participação das/os trabalhadoras/es de forma a valorizar uma das conquistas centrais do Sistema quanto a inovação do fortalecimento da democracia e da cidadania por meio das diversas organizações representativas.

Quanto aos achados sobre os aspectos que faz da Assistência Social uma política regular, encontramos: falta e/ou descontinuidade na oferta dos benefícios eventuais; ausência de formação/capacitação continuada para as/os trabalhadoras/es; insuficiência de recursos/materiais de trabalho e pouca valorização das/os trabalhadoras/es.

Estas descobertas, podem ser melhor compreendidas nas falas que seguem:

\footnotetext{
A política se encontra fragilizada na perspectiva de conseguir garantir com efetivação os direitos dos cidadãos, principalmente em relação aos benefícios eventuais, como cestas básicas e kit bebê, além do processo de complexidade para garantir o acesso ao aluguel social [...] (INFORMANTE 15).

[...] Percebe-se também uma grande precarização em relação aos benefícios eventuais, pois já estamos quase no final do ano, e ainda não teve nenhuma oferta. Some-se a isso, a absoluta falta de formação continuada para os profissionais de nível médio (INFORMANTE 02).

[...] Insuficiência de recursos materiais para uma efetivação qualitativa dos serviços ofertados nos equipamentos, ausência de formação continuada para os profissionais [...] (INFORMANTE 10).
} 
Ainda sobre avaliação que as/os profissionais fazem da referida política, colhemos que as análises em torno da estrutura física e da presença de equipamentos sociais para realização dos serviços, a coloca como boa. Repetem-se falas reiterando que o município se diferencia de outros pela presença de uma variedade de equipamentos sociais, os quais possibilitam o desenvolvimento das atividades de forma descentralizada, mantendo-se aliadas a PNAS no que tange a organização territorial e cobertura dos serviços, como estratégia de fortalecimento dos vínculos com as famílias acompanhadas pelo CRAS.

O município conta com diversos equipamentos sociais para a garantia de direitos funcionando de forma descentralizada e participativa, faltando apenas, em casos pontuais, uma melhor articulação e comunicação entre esses equipamentos (INFORMANTE 07).

Diante da realidade social e econômica do município de Iguatu é de importância destacar a existência de seis CRAS funcionando com a equipe mínima. Boa, mas que há imensos desafios como: recursos financeiros baixos, equipe mínima para uma grande demanda e super valorização de alguns profissionais em detrimento de outros [...] (INFORMANTE 25).

Corroborando com as avaliações no que tange a estrutura municipal, o informante 09 reitera que o município dispõe de uma estrutura organizativa condizente com o SUAS, porém ainda necessita avançar no sentido da capacitação profissional.

A presença de CRAS em todos os territórios revela um importante avanço para a política municipal ao passo que a coloca em conformidade com o que preconiza as orientações técnicas quanto à oferta dos serviços socioassistenciais, estas expressam claramente a necessidade de espaços púbicos para oferta destes e imprime obrigatoriedade de que o PAIF, um dos principais serviços da PSB, aconteça exclusivamente em espaço público, sendo o CRAS o local destinado para este fim.

O trabalho social com famílias do PAIF é desenvolvido pela equipe de referência do CRAS e a gestão territorial pelo coordenador do CRAS, auxiliado pela equipe técnica, sendo, portanto, funções exclusivas do poder público e não de entidades privadas de assistência social (CADERNOS DE ORIENTAÇÕES SOBRE O CRAS, 2009, p. 10).

Sobre a avaliação que a representante do FMTSUAS faz da política municipal de Assistência Social, colhemos, a partir de suas falas, que a mesma vivencia um processo de avanço e recuo, quer seja em nível nacional e/ou municipal. Para ela, ainda é possível perceber manifestações de cunho assistencialista na sua execução, sobretudo, na condução que tem sido 
dada pelas gestões municipais. A mesma coloca ainda a recorrente dificuldade para efetivação dos serviços e benefícios, a exemplo dos benefícios eventuais, que historicamente não conseguem manter uma periodicidade na sua concessão, o que corrobora com a maioria dos achados nas falas das/os informantes.

[...] os benefícios eventuais agora que os CRAS estão recebendo as cestas básicas e os kits bebê a gente nem tem noção, estes benefícios que é um direito, que não é caridade [...] mesmo a gente sabendo que estes benefícios são imediatos, ele vai sanar a fome ou serve para aquela família que está num situação extrema de vulnerabilidade naquele momento, mas passou muito tempo, a gente sabe que há famílias que a única renda é a do Bolsa Família, que estas pessoas não tem condições nem de se alimentar, que tem que escolher ou come ou paga aluguel [...] (ENTREVISTADA FMTSUAS).

Ainda de acordo com a entrevista uma questão que tem contornado a gestão da Assistência Social em Iguatu é a presença da primeira-dama como secretária municipal. Para a representante do FMTSUAS esta relação acaba por confundir até mesmo as/os trabalhadoras/es e usuários/as na forma como se referir à gestora municipal. Cabe destacar que esta revelação recoloca em cena a estreita e histórica relação entre público e privado no Estado brasileiro, sobretudo, quando se trata da gestão da política de Assistência Social.

[...] aqui no município de Iguatu a primeira dama ocupando a gestão da secretaria municipal de assistência, quer queira, quer não, não levando para o lado pessoal, a pessoa, a primeira dama, a figura, aquela mulher, mas a gente ver que acaba destituindo, tendo aquela visão daquela mulher boazinha, atrela sempre a figura da primeira dama, tanto é que dificilmente a gente se remete a ela como a secretária, $e$ sim como a primeira dama, então fica difícil, é complicado até para o trabalhador tratar algo com a gestora sem remeter ao prefeito, então um usuário que vai, que precisa falar com ela, vai sempre remeter a primeira dama, vai sempre remeter a figura do prefeito, ela deixa o âmbito privado e vai para o publico e isso não é bom, isso e um retrocesso para a política municipal de assistência [...] (ENTREVISTADA FMTSUAS).

Em contraponto, a entrevistada coloca alguns avanços que tem percebido na oferta dos serviços, em especial neste ano e a partir das lutas das/os trabalhadoras/es, a mesma coloca " a gente ver uma melhoria na qualidade do lanche que são oferecidos nos CRAS, o material, está chegando atualmente muito material para que seja trabalhado no SCFV, principalmente no SCFV, não falta material de expediente para outros trabalhos", conclui.

As análises acumuladas ao longo das falas revelam uma importante perspectiva de avanço, ainda que gradual, no que tange a efetivação da política municipal de Assistência Social em Iguatu, ao passo que acenam para um promissor processo de fortalecimento e consolidação 
da organização política das/os suas/seus trabalhadoras/es. Destacamos, portanto, que estes processos se revelaram contornados de contradições, e, uma melhor apreensão destes demanda colocá-los em relação dialética, ora numa expectativa de avanços, ora como retrocessos, a depender do movimento de cada período histórico.

\section{Considerações Finais}

O traçado metodológico que adotamos na realização deste estudo teve como objetivo analisar o processo de organização política das/os trabalhadoras/es do SUAS em Iguatu, com foco na Proteção Social Básica/CRAS. Ao longo da pesquisa nos propomos a perceber o processo histórico de constituição da Assistência Social enquanto política de Seguridade Social, bem como a criação e implementação do SUAS, destacando para tanto, as lutas empreendidas nos últimos anos para que esta conquista tornar-se uma realidade no processo de organização política administrativo da Assistência Social no Brasil.

O acúmulo realizado ao longo da pesquisa nos possibilitou compreender os significativos avanços incididos na conformação da Assistência Social como política de Seguridade Social. Desde então, percebemos um intenso investimento em sua organização político e administrativa, sobretudo, no que tange a elaboração de normatizações que possibilitaram claramente sua operacionalização, ao passo que reafirmou seu caráter de política pública de direito, sob primazia do Estado e direito social assegurado a quem dela necessitar.

Importa destacar que, embora tenham ocorrido conquistas estruturais significativas ao longo dos anos, este processo não se deu de forma linear, pelo contrário, foi historicamente tensionado ora por avanços, ora por retrocessos, ambos consoantes com a lógica política e econômica hegemonizada pelo Estado brasileiro.

Nesta perspectiva destacamos que a cidade de Iguatu não ficou ilesa a estes acontecimentos, o que nos permite inferir que a operacionalização da Política Municipal de Assistência Social igualmente foi contornada por alternados processos de conquistas e retrocessos.

Como anunciamos, nosso principal intento com esta investigação, estava centrada em analisar a organização política das/os trabalhadoras/es do SUAS em Iguatu. Em contraponto, reafirmamos que nem de longe pretensionamos que essas análises sejam vistas como "verdade", 
contudo, precisam ser compreendidas como apontamentos do real, os quais seguramente desencadearão novas análises e novos posicionamentos, em um contínuo processo críticodialético.

Partindo desse entendimento, lançamos agora a explicitar os fatores percebidos ao longo deste estudo, os quais, em graus distintos, incidem diretamente no processo de organização política das/os informantes. Toda nossa abordagem foi colocada em uma perspectiva de totalidade, compreendendo, pois, que cada sujeito é contornado por um conjunto de fatores que por vezes são alheios as suas manifestações ou vontades particularizadas.

Percebemos, portanto, que nos últimos anos houve um intenso processo de luta e organização coletiva das/os trabalhadoras/es. A articulação das lutas locais consoantes com as demandas emergidas na sociedade brasileira a partir da reconfiguração da conjuntura do país após o golpe de 2016, possibilitaram o surgimento de um intenso e mobilizador processo de aglutinação das forças das/os trabalhadoras/es municipais em lutar por seus direitos e por melhores condições de trabalho no serviço público municipal. Para, além disso, acrescentamos ainda a autonomia das/os servidoras/es municipais, os quais, na grande maioria, são oriundas/os dos últimos concursos públicos. Muitas das falas colhidas na pesquisa enalteceram que as lutas empreendidas pelas/os trabalhadoras/es só foram possíveis por que estas/es não acessaram o serviço público via articulações políticas e eleitorais, o que lhes permitiam lutar por seus diretos e por melhores condições de trabalho.

Estes acontecimentos aparecem como umas das principais motivações para uma maior organização das/os trabalhadoras/es em espaços coletivos, a exemplo, do Sindicato de Servidores Público Municipal de Iguatu - SSPUMI e o Fórum Municipal de Trabalhadoras/es do SUAS - FMTSUAS. As duas organizações apareceram de forma majoritária como os principais instrumentos de luta e organização utilizados pelas/os trabalhadoras/es no âmbito do SUAS. Como mencionamos, estes instrumentos são considerados no âmbito do SUAS como ferramentas inovadoras de participação social, bem como de ampliação dos tradicionais mecanismos de controle social, a exemplos dos conselhos de direitos e conferências de políticas públicas.

Evidenciamos, ainda, a partir do universo pesquisado e com bases nos achados da pesquisa que a estrutura técnica das equipes de referências dos CRAS encontram-se em acordo com as resoluções e normativas da Política Nacional de Assistência Social bem como a Norma 
Operacional Básica de Recursos Humanos, bem como as condições de infraestrutura e espaços físicos onde são desenvolvidos os serviços ofertados pela Proteção Social Básica.

Portanto, cabe-nos afirmar, a partir de processo investigativo desta pesquisa, que é inegável os avanços e as conquistas no que concerne a organização política das/os trabalhadoras/es do SUAS em Iguatu, ao passo que ratificamos que esta movimentação coletiva no bojo da luta de classes permitiu o alcance e a materialidade de direitos trabalhistas historicamente negados pelas gestões municipais, promoveu melhores condições de trabalho, e, sobretudo, possibilitou, através da articulação de pautas reivindicatórias locais e nacionais uma maior identidade de classe trabalhadora, superando, a perspectiva reducionista de pautar a luta por direitos apenas aos interesses das categorias profissionais.

Almejamos, nos limites e possibilidades desta pesquisa, termos contribuído para novas análises e investigações acerca das formas de organização política e participação social no âmbito do SUAS, reafirmando, portanto, que a consolidação do SUAS, perpassa substancialmente por amplos processos democráticos e participativos, bem como a efetivação da política de Assistência Social, esta pautada no enfrentamento de toda e qualquer perspectiva conservadora e/ou assistencialista, elevando-a cada dia mais ao patamar de política pública de direito, consoante com os objetivos e princípios constitucionais.

\section{Referências}

ABRAMIDES, Maria Beatriz Abramides; DURIGUETTO, Maria Lúcia. (Orgs.). Movimentos Sociais e serviço social: uma relação necessária. São Paulo: Cortez, 2014.

BRASIL, Constituição da República Federativa do Brasil. Capítulo II - Da Seguridade Social, Título VII - Da Ordem Social, 1988.

Ministério do Desenvolvimento Social e Combate à Fome. Política Nacional de Assistência Social. Brasília, DF: SNAS/MDS, 2004.

Ministério do Desenvolvimento Social e Combate à Fome. Norma Operacional Básica do Sistema Único de Assistência Social (NOB/SUAS). Brasília, DF: SNAS/MDS, 2005.

, Ministério do Desenvolvimento Social e Combate à Fome. Norma Operacional Básica de Recursos Humanos dos SUAS (NOB/RH/SUAS). Brasília, DF: SNAS/MDS, 2011. 
Ministério do Desenvolvimento Social e Combate à Fome. Tipificação Nacional de Serviços Socioassistenciais. Brasília, DF: MDS/SNAS, 2009.

, Ministério do Desenvolvimento Social e Combate a Fome. Orientações Técnicas:

Centro de Referência de Assistência Social - CRAS. Brasília, DF: MDS, 2009.

Ministério do Desenvolvimento Social e Combate a Fome. Lei Orgânica da Assistência Social . Brasília, DF: MDS, 2011.

CAREGNATO, R.C.A.; Mutti, R. pesquisa qualitativa: análise de discurso versus análise de conteúdo. Texto Contexto Enferm, Florianópolis, 2006 Out-Dez; 15(4): 679-84. Disponível em: 〈http://www.scielo.br/pdf/tce/v15n4/v15n4a17.pdf〉. Acesso em: 12 Nov. 2017.

CISNE, Mirla. A "feminização" da Assistência Social: apontamentos históricos para uma análise de gênero. III Jornada Internacional de Políticas Públicas São Luís - MA, 2007. Disponível

em: <http://www.joinpp.ufma.br/jornadas/joinppIII/html/Trabalhos/EixoTematicoD/6912b8f5264 e3ab9992bMIRLA_CISNE.pdf >. Acesso em: 14 Out. 2017.

COUTO, Berenice Rojas. et al. O Sistema Único de Assistência Social no Brasil: uma realidade em movimento. São Paulo: Cortez, 2010.

GIL, Antonio Carlos. Como elaborar projetos de pesquisa. 4. ed. São Paulo: Atlas, 2002.

GONDIM, Linda Maria de Pontes. O projeto de pesquisa no contexto do processo de construção do conhecimento. Pesquisa em Ciências Sociais: o projeto da dissertação de mestrado. Fortaleza: Eufc, 1999.

IAMAMOTO, Marilda Vilela: O Serviço Social na contemporaneidade: trabalho e formação profissional /Marilda Vilela Imamamoto. 20. Ed. - São Paulo, Cortez, 2011

Relações Sociais e Serviço Social no Brasil: esboço de uma interpretação históricometodológica. 25. ed. -2008.

MARCONI, M. A .; LAKATOS, E.M. Metodologia Científica. São Paulo: Atlas. 2000.

MARICATO, Ermínia. Cidades Rebeldes: Passe Livre e as manifestações que tomaram as ruas do Brasil. 1 ed. - São Paulo: Boitempo: Carta Maior, 2013.

MARX, Karl. Manifesto do Partido Comunista. 1. Ed - São Paulo: Expressão Popular, 2008.

MINAYO, Maria Cecília de Souza. O desafio do conhecimento: pesquisa qualitativa em saúde. 14 ed.- Hucitec Editora, 2014.

Pesquisa Social: Teoria, método e criatividade. Petropólis: Vozes, 1994. 
ROCHA, Flávia Rebecca Fernandes. A unidade contraditória da assistência e da previdência social: uma análise política da execução orçamentárias no governo Lula Fortaleza: EDUECE, 2016.

SANTOS, Josiane Soares: Neoconservadorismo pós-moderno e serviço social brasileiro. São Paulo: Cortez, 2007.

SILVA, Luciana Sátiro. Ética e Serviço Social: a percepção das assistentes sociais sobre suas práticas profissionais nos Centros de Referências de Assistência Social de Fortaleza- CE. Dissertação (Mestrado Acadêmico em Serviço Social, Trabalho e Questão Social) Universidade Estadual do Ceará, Centro de Estudos Sociais Aplicados, Fortaleza, 2014.

SILVA, Mossicléia Mendes da. Projeto ético-político e assistência social: um estudo do cotidiano de trabalho dos (as) assistentes sociais do Centro Sul/Vale do Salgado-CE. Dissertação (Mestrado) Universidade Estadual do Rio de Janeiro, Faculdade de Serviço Social, 2013.

\section{Como citar este artigo (Formato ABNT):}

LIMA, Rita de C. C. de; GOMES FILHO, Antoniel dos S. A Organização Política das/os Trabalhadoras/es do SUAS no Âmbito da Proteção Social Básica de Iguatu-CE. Id on Line Revista Multidisciplinar e de Psicologia, 2018, vol.12, n.40, p.32-58. ISSN: 1981-1179.

Recebido: 08.10.2017

Aceito: 10.02 .2018 